\title{
Rationale and design of the Eplerenone in Mild Patients Hospitalization And Survlval Study in Heart Failure (EMPHASIS-HF)
}

\author{
Faiez Zannad ${ }^{1 *}$, John J.V. McMurray ${ }^{2}$, Helmut Drexler ${ }^{3 \dagger}$, Henry Krum ${ }^{4}$, \\ Dirk J. van Veldhuisen ${ }^{5}$, Karl Swedberg ${ }^{6}$, Harry Shi ${ }^{7}$, John Vincent ${ }^{7}$, and Bertram Pitt ${ }^{8}$
}

\begin{abstract}
${ }^{1}$ Inserm, Centre d'Investigation Cliniques CIC 9501 and U961, CHU and Department of Cardiology, Nancy University, Nancy, France; ${ }^{2}$ British Heart Foundation Cardiovascular Research Centre, University of Glasgow, Glasgow, UK; ${ }^{3}$ Clinic of Cardiology and Angiology, Hannover Medical School, Hannover, Germany; ${ }^{4}$ Department of Epidemiology and Preventive Medicine, Centre of Cardiovascular Research and Education in Therapeutics, Monash University, Melbourne, Australia; ${ }^{5}$ Department of Cardiology, Thorax Centre, University Medical Centre, Groningen, The Netherlands; ' ${ }^{6}$ epartment of Emergency and Cardiovascular Medicine, Sahlgrenska Academy, University of Gothenburg, Göteborg, Sweden; ${ }^{7}$ Pfizer, Inc., New York, NY, USA; and ${ }^{8}$ University of Michigan, Ann Arbor, MI, USA
\end{abstract}

Received 12 February 2010; accepted 16 February 2010; online publish-ahead-of-print 13 April 2010

Aims

In chronic heart failure (HF), aldosterone antagonists have been shown to improve survival in patients with low ejection fraction and moderate-to-severe symptoms [New York Heart Association (NYHA) classes III and IV]. Efficacy of these agents was also shown when they were administered to patients with left ventricular dysfunction and signs and symptoms of CHF early after acute myocardial infarction. It is not known whether the selective aldosterone antagonist eplerenone can improve outcomes in mildly symptomatic patients. The Eplerenone in Mild Patients Hospitalization And Survlval Study in Heart Failure (EMPHASIS-HF) was designed to evaluate the effect of eplerenone on mortality and morbidity in patients with chronic systolic HF in NYHA class II.

Methods Approximately 3100 patients with ejection fraction $\leq 30 \%$ and estimated glomerular filtration rate $\geq 30 \mathrm{~mL} / \mathrm{min} /$ $1.73 \mathrm{~m}^{2}$ will be recruited. Patients are randomized 1:1 to double-blind eplerenone or placebo in addition to standard chronic HF therapy. Doses are adjusted from $25 \mathrm{mg}$ every other day to $50 \mathrm{mg}$ daily, depending on serum potassium. The primary endpoint is a composite of time to cardiovascular death or first hospital admission for worsening HF, whichever occurs first.

Conclusion The study will be complete when approximately 813 subjects experience a primary endpoint.

Clinical Trials.gov. NCT00232180.

Keywords

Systolic heart failure - Clinical trial • Outcome • Aldosterone antagonist • Eplerenone

\section{Introduction}

Aldosterone plays an important role in the pathophysiology of heart failure (HF), ${ }^{1,2}$ and mineralocorticoid receptors (MRs) are over-expressed in the myocardium of the failing heart. ${ }^{3,4}$ Despite chronic angiotensin-converting enzyme (ACE)-inhibitor (ACE-I) therapy, ${ }^{5,6} \beta$-blocker therapy, ${ }^{7}$ and angiotensin receptor blocker (ARB) therapy, ${ }^{8}$ patients with even mild symptoms of HF have elevated plasma aldosterone levels, ${ }^{9}$ although combined ACE and ARB therapy was recently reported to give a sustained decrease in aldosterone levels. ${ }^{10}$
In patients with a low left ventricular ejection fraction (LVEF) and severe symptoms [New York Heart Association (NYHA) class III or IV], adding the aldosterone (receptor) blocker (AB) spironolactone $25 \mathrm{mg}$ daily to standard therapy (ACE-I and loop diuretic) resulted in a $30 \%$ reduction in the relative risk of all-cause mortality in the placebo-controlled Randomized Aldactone Evaluation Study (RALES). Spironolactone treatment also resulted in a $35 \%$ lower frequency of hospitalization for worsening HF. ${ }^{11}$ However, RALES only enrolled patients with severe HF and signs of volume overload, and few received $\beta$-blocker therapy. In patients with acute myocardial infarction (MI) complicated by left

\footnotetext{
* Corresponding author: FESC CIC INSERM CHU, Hôpital Jeanne d' Arc, Toul 54200, France. Tel: +33 383656625 , Fax: +33 3836566 19, Email: f.zannad@chu-nancy.fr † In memoriam.

Published on behalf of the European Society of Cardiology. All rights reserved. (C) The Author 2010. For permissions please email: journals.permissions@oxfordjournals.org.
} 
ventricular systolic dysfunction (LVSD) and HF, adding the more selective $A B$ eplerenone to optimal medical therapy, including ACE-Is and $\beta$-blockers, reduced morbidity and mortality in the Eplerenone Post-Acute Myocardial Infarction Heart Failure Efficacy and Survival Study (EPHESUS). ${ }^{12}$ Consequently, current guidelines recommend $\mathrm{ABs}$ in patients with low $\mathrm{EF}(<35 \%)$ and moderateto-severe (NYHA class III and IV) HF and in selected patients after acute $\mathrm{MI}^{13}$

The efficacy, safety, and tolerability of $A B$ have not been systematically evaluated in a large-scale, prospective, randomized study of patients with LVSD and mild chronic HF.

Although patients with LVSD may be clinically stable showing few, if any, symptoms for long periods of time, their clinical course may be complicated by frequent hospital admissions for worsening $\mathrm{HF}$ and a relatively high rate of cardiovascular (CV) mortality, the most frequent mode being sudden cardiac death. ${ }^{14}$

The aim of the Eplerenone in Mild Patients Hospitalization And Survlval Study in Heart Failure (EMPHASIS-HF) is to investigate the effects of eplerenone vs. placebo added to fully optimized therapy including an ACE-I (or/and an ARB) and $\beta$-blocker in patients with mild (NYHA functional class II) chronic HF with low EF.

\section{Study design}

EMPHASIS-HF is a multicentre, randomized, double-blind, placebo-controlled study.

The primary objective of this trial is to evaluate the efficacy and safety of eplerenone plus standard HF therapy vs. placebo plus standard HF therapy on the cumulative incidence of the composite endpoint of $\mathrm{CV}$ death or HF hospitalization, defined as the first occurrence of either HF hospitalization or $\mathrm{CV}$ death. The secondary endpoints are the first occurrence of allcause mortality or HF hospitalization, all-cause mortality, CV mortality, all-cause hospitalization, HF hospitalization, all-cause mortality or all-cause hospitalization, HF mortality or HF hospitalization, CV hospitalization, fatal/non-fatal myocardial infarction, fatal/non-fatal stroke, days alive and out of hospital at one year, implantation of a cardiac defibrillator, implantation of a resynchronization device, new-onset atrial fibrillation/flutter, new-onset diabetes mellitus, worsening renal function (if it results in hospitalization), and hospitalization for hyperkalaemia. For all events both the total number of patients experiencing the event as well as the total number of events will be analysed.

\section{Patient enrolment criteria}

\section{Inclusion criteria}

Male and female patients aged 55 years or over with the following criteria are eligible.

(1) A diagnosis of chronic HF and LVSD of either ischaemic or non-ischaemic aetiology or inoperable valve disease.

(2) Duration of HF must be at least 4 weeks.

(3) Left ventricular ejection fraction $\leq 30 \%$ by echocardiography, contrast ventriculography, magnetic resonance imaging (MRI) or nuclear imaging within 6 months of randomization, or LVEF $\leq 35 \%$ in addition to QRS duration $>130$ ms. Subjects with LVEF $31-35 \%$ must have QRS duration $>130$ ms to be eligible.

(4) New York Heart Association functional class II at randomization.

(5) Treatment with optimal target or maximal tolerated dose of ACE-I and/or ARB and $\beta$-blocker, unless contra-indicated, as well as diuretics if clinically indicated.

(6) Serum potassium $\left(\mathrm{K}^{+}\right) \leq 5.0 \mathrm{mmol} / \mathrm{L}$ within $24 \mathrm{~h}$ prior to randomization.

(7) Estimated glomerular filtration rate (eGFR), using the Modification of Diet in Renal Disease (MDRD) six-variable formula, $\geq 30 \mathrm{~mL} / \mathrm{min} / 1.73 \mathrm{~m}^{2}$ within $24 \mathrm{~h}$ prior to randomization.

(8) Randomization must occur within 6 months of a hospitalization for $\mathrm{CV}$ reasons. In the absence of a history of hospitalization for $\mathrm{CV}$ reasons, documented plasma B-type natriuretic peptide (BNP) of at least $250 \mathrm{pg} / \mathrm{mL}$ or $\mathrm{N}$ terminal proBNP (NT-proBNP) $\geq 500 \mathrm{pg} / \mathrm{mL}$ for males and $\geq 750 \mathrm{pg} / \mathrm{mL}$ for females within 15 days prior to randomization. Cardiovascular hospitalization is defined as hospitalization for HF, acute MI, unstable angina pectoris, cardiac arrhythmia, stroke, or other $\mathrm{CV}$ reasons such as peripheral arterial disease or hypotension. Hospitalization for an elective CV procedure does not qualify for entry into this trial except hospitalization for implantation of a cardioverter-defibrillator (ICD) or cardiac resynchronization therapy (CRT) device.

(9) Subjects previously treated with an $A B$ for more than 7 consecutive days must meet the following additional criteria:

(a) No history of clinically significant hyperkalaemia or renal impairment during previous $A B$ therapy.

(b) Aldosterone blocker therapy discontinued for at least 3 months prior to randomization. Investigators were instructed not to stop $A B$ in patients just to enter the trial.

\section{Exclusion criteria}

Patients are not eligible for enrolment if they present any of the following criteria:

- an indication for $A B$ treatment according to current $H F$ guidelines $^{13}$;

- history of stroke, cardiac surgery, or percutaneous coronary intervention within 30 days prior to randomization;

- uncontrolled hypertension [systolic blood pressure (SBP) $>180 \mathrm{mmHg}$ and/or a diastolic blood pressure $>110 \mathrm{mmHg}]$ or symptomatic hypotension, or an SBP $<85 \mathrm{mmHg}$;

- need for adjunctive potassium-sparing diuretic therapy;

- an intra-aortic balloon pump or any other mechanical assist device;

- scheduled for cardiac transplantation;

- serum potassium $>5.0 \mathrm{mmol} / \mathrm{L}$ within $24 \mathrm{~h}$ prior to randomization;

- estimated glomerular filtration rate $<30 \mathrm{~mL} / \mathrm{min} / 1.73 \mathrm{~m}^{2}$ within $24 \mathrm{~h}$ prior to randomization;

- following concomitant therapy with potent cytochrome P4503A4 inhibitors or inducers;

- blood haemoglobin <10 g/dL; 
- any other pre-existing and ongoing significant co-morbid condition.

\section{Dosing regimen}

Subjects are started on eplerenone or matching placebo at doses of $25 \mathrm{mg}$ once daily if eGFR is $\geq 50 \mathrm{~mL} / \mathrm{min} / 1.73 \mathrm{~m}^{2}$, and $25 \mathrm{mg}$ every other day if eGFR is $30-49 \mathrm{~mL} / \mathrm{min} / 1.73 \mathrm{~m}^{2}$. At 4 weeks, provided that serum potassium is $\leq 5.0 \mathrm{mmol} / \mathrm{L}$, the dose of study drug may be increased to $50 \mathrm{mg}$ once daily if eGFR $\geq 50 \mathrm{~mL} / \mathrm{min} / 1.73 \mathrm{~m}^{2}$ and to $25 \mathrm{mg}$ once daily if eGFR is in the range of $30-49 \mathrm{~mL} / \mathrm{min} / 1.73 \mathrm{~m}^{2}$. Study drug dose adjustment or dose maintenance is guided by safety considerations, mainly by changes in serum potassium and eGFR which are monitored at each visit. Investigators are instructed to decrease the dose if potassium is $>5.5 \mathrm{mmol} / \mathrm{L}$ or withhold the dose if potassium is $>6.0 \mathrm{mmol} / \mathrm{L}$, and to recheck potassium within $72 \mathrm{~h}$ and only restart the dose once potassium drops to $<5.0 \mathrm{mmol} / \mathrm{L}$.

\section{Statistical considerations}

\section{Sample size determination}

The study was initially designed to enrol a total sample size of 2584 randomized subjects (1292 per treatment group) with at least $80 \%$ power to detect an $18 \%$ risk reduction in the primary efficacy endpoint. This is based on the two-sided log-rank test for between-treatment comparison in the time to first occurrence of $\mathrm{CV}$ mortality or hospitalization for HF (a composite endpoint) at a $5 \%$ level of significance, assuming an annual event rate of $18 \%$ and a $5 \%$ annual dropout rate. For a group-sequential trial with three equal interval efficacy looks (two interim analyses and the final analysis at trial completion), an expected annual event rate of $18 \%$, a subject enrolment period of 18 months at most, an endpoint accrual period of 30 months, an assumed exponential dropout rate of 5\% per year, and a sample size of 2584 (1292 per treatment group), randomized subjects will be followed until 813 primary events (CV death or HF hospitalization) have occurred.

During the course of the study, a lower than anticipated overall event rate prompted us to amend the protocol by increasing sample size to 3100 patients.

\section{Efficacy analysis}

The efficacy analysis will be performed on the intent-to-treat population. The time-to-event distributions will be summarized by treatment group using Kaplan-Meier estimates of cumulative incidence. Cox's proportional hazards regression model will be used for adjusting the following baseline prognostic factors: age, eGFR, LVEF, body mass index, haemoglobin, heart rate, SBP, diabetes, history of hypertension, prior MI, atrial fibrillation, and left bundle branch block (LBBB) or QRS >130 ms.

In addition, the primary efficacy endpoint will be analysed on the following pre-specified subgroups for subjects' baseline characteristics: gender, age ( $<65$ and $\geq 65$ years), region (Western Europe/ Australia, Eastern Europe, Asia/Middle East/Africa, and South/ North America), baseline SBP and pulse pressure (less than or equal to median and greater than median), heart rate (less than or equal to median and greater than median), eGFR ( $\leq 50$ and $>50 \mathrm{~mL} / \mathrm{min} / 1.73 \mathrm{~m}^{2}$ ), LVEF ( $\leq 30$ and $>30 \%$ ), LBBB, atrial fibrillation, diabetes (yes and no), and aetiology of HF (ischaemic and non-ischaemic HF), prior use of triple neurohumoral blockers ( $\beta$-blocker plus ACE-I plus ARB), prior use of $\beta$-blocker, prior use of ACE-I or ARB, history of hypertension, period of prior CV hospitalization ( $\leq 180$ days and $>180$ days), prior CRT, prior ICD, and QRS $>130 \mathrm{~ms}$.

\section{Safety analysis}

For all subjects who took at least one dose of study medication (eplerenone or placebo), the incidence, severity, and relationship to the study drug of treatment-emergent adverse events will be summarized by body system and treatment groups. In addition, the incidence of adverse events causing study drug discontinuation and serious adverse events will be summarized per treatment group. Incidence of marked abnormalities in the protocol-specified laboratory tests will be summarized per treatment group.

\section{Trial oversight}

An independent Executive Steering Committee in conjunction with the sponsor will oversee the conduct of the trial. An independent Endpoint Adjudication Committee will review the documentation on clinical endpoint events and determine whether the events meet the pre-specified criteria. An independent Data Safety Monitoring Committee (DSMC) will monitor the safety and efficacy of the trial and periodically assess whether the trial should continue as planned (Appendix).

\section{Statistical decision rules and interim analyses}

All hypothesis tests will be two-sided. Results will be considered statistically significant if a $P$-value $<0.05$ is obtained for primary hypotheses (adjusting for two interim analyses; see the discussion on interim analyses in what follows). Interim analyses examining the primary efficacy endpoint will be performed after a total of approximately 271 and 542 primary endpoint events have occurred. At the accrual of 542 primary endpoints, the DSMC may recommend the trial be terminated if either an overwhelming benefit (two-sided $P$-value $<0.001$ in favour of eplerenone) or an overwhelming harm (two-sided $P$-value $<0.01$ against eplerenone) is observed. In addition, the trial will be recommended for termination in the event of excessive all-cause mortality ascribable to eplerenone treatment $(P$-value $<0.01)$ at any of the interim looks. Using an adaptation of the Haybittle-Peto stopping criterion, the $P$-value for the final primary analysis will be compared with $\alpha=0.049$. No adjustment in $\alpha$ will be made for any looks on parameters/endpoints other than the primary composite endpoint.

\section{Current status}

EMPHASIS-HF started enrolling patients in March 2006. As of February 2010, it had enrolled 2600 patients in 272 centres and 29 countries distributed across all of the major regions worldwide. Study completion date is estimated at October 2011.

\section{Discussion}

The combination of an ACE-I and a $\beta$-blocker forms the core basis of therapy for patients with HF and low LVEF. These drugs have been proved to decrease morbidity and mortality in patients with HF across the full spectrum of symptoms (NYHA classes II-IV). ${ }^{15,16}$ 
To date, the efficacy of $A B$ s has only been proved in patients with severe symptoms (NYHA classes III and IV) and in patients with low LVEF and clinical evidence of HF (or diabetes) after acute MI. ${ }^{11,12}$

\section{Patient population}

Patients with visibly 'mild' symptoms may nevertheless present severe underlying ventricular dysfunction, and the prognosis outcome over a 2-to-3-year period after initial diagnosis may be poor. The event rate in such patients is usually high, though relatively lower than for patients with moderate-to-severe symptoms. ${ }^{14}$ Apart from the now-dated Studies Of Left Ventricular Dysfunction (SOLVD) prevention study, ${ }^{17}$ no large-scale studies have focused exclusively on patients with mild symptoms at the time of randomization. EMPHASIS-HF will therefore provide important information on the contemporary natural history of these patients as well as on the impact of $A B$ s in this setting.

A low event rate is a challenging feature in any outcome trial, requiring a large population sample size. In EMPHASIS-HF, in order to spare sample size, we elected to enrich the event rate by selecting patients aged $>55$ years. In addition, we restricted enrolment to patients with a history of recent CV hospitalization or a high BNP value. Data from the SOLVD ${ }^{17,18}$ study as well as from the Candesartan in Heart failure: Assessment of Reduction in Mortality and morbidity (CHARM) trial $^{19}$ underline that a recent history of HF hospitalization is consistently reported to be associated with a subsequently higher event rate.

Since LVEF is inversely associated with the outcome, we also set the inclusion LVEF at the relatively low level of $<30 \%$, whereas for patients with an LVEF ranging 30-35\%, we added the additional risk factor requirement of QRS duration $>130 \mathrm{~ms}$. This was prompted by the fact that QRS prolongation is associated with a worse outcome in HF patients. ${ }^{20}$

\section{Aldosterone blockers in patients with chronic mild heart failure}

Current HF guidelines do not recommend the use of $A B s$ in patients with mild symptoms of HF. European Society of Cardiology HF guidelines state that, unless contra-indicated or not tolerated, ABs should be considered in patients with low LVEF $(<35 \%)$ and moderate-to-severe symptoms, i.e. NYHA classes III and IV, in the absence of hyperkalaemia and significant renal dysfunction (Class of recommendation I, Level of Evidence B). ${ }^{13}$

Few studies have investigated the effect of $A B s$ specifically in patients with chronic mild-to-moderate systolic HF, and those that have been published enrolled a small number of patients and investigated the effect of $A B s$ on surrogate endpoints. None was adequately powered to investigate mortality and morbidity outcomes. ${ }^{9,21-24}$ All are covered in the systematic review by Ezekowitz and McAlister. ${ }^{25}$ One relatively large study, the Antiremodelling effect of canrenone in patients with mild chronic heart failure (AREA IN-CHF), was a randomized, double-blind, parallel-group comparison of canrenone (up to $50 \mathrm{mg} /$ day), the active metabolite of spironolactone, against placebo in mild stable HF. ${ }^{9}$ The primary endpoint was change in echocardiographic LV end-diastolic volume over 12 months. Patients had NYHA class II HF, LVEF $\leq 45 \% .^{21}$ Left ventricular end-diastolic volume was similarly reduced in both arms, but LVEF increased more $(P<0.04)$ in the canrenone arm (from 40 to $45 \%)$ than in the placebo arm (from 40 to 43\%). B-type natriuretic peptide decreased more in the canrenone arm (37\%) than in the placebo arm (8\%; $P<0.0001)$. The composite endpoint of cardiac death and hospitalization was significantly lower in the canrenone arm ( 8 vs. $15 \% ; P<0.02$ ). The authors concluded that canrenone on top of optimal treatment for HF did not have additional effects on LVEDV but increased LVEF. ${ }^{21}$ However, the number of clinical events in this study was relatively small $(n=382)$ and it was therefore unlikely to influence current guidelines and clinical practice.

The Reversal of Cardiac Remodelling with Eplerenone trial (REMODEL) investigated the effects of eplerenone compared with placebo on ventricular remodelling assessed by radionuclide ventriculography in 226 patients presenting with mild-to-moderate $\mathrm{HF}$ and left ventricular dysfunction. Eplerenone did not provide any additional benefit on LV remodelling in these patients over the 9-month duration of the study. ${ }^{26}$

\section{Study endpoints}

The primary endpoint of EMPHASIS-HF is the cumulative incidence of the composite endpoint of CV death or hospitalization for HF. This cause-specific endpoint is the most frequently used primary endpoint in recent and ongoing HF trials. All-cause mortality as a primary endpoint would have been more integrative and more robust. However, eplerenone is not expected to have any effect on non-CV deaths, and this endpoint might lead to a dilution of the expected benefit together with a loss of power, requiring an even larger sample size.

Several new secondary pre-specified endpoints are included in the protocol with the aim of generating new hypotheses. Given the potential effects of $A B s$ on cardiac remodelling and electrophysiology, the study will investigate the effect of eplerenone on the implantation of cardiac defibrillators and/or resynchronization device implantation and of new-onset atrial fibrillation/flutter. New-onset diabetes mellitus will also be recorded in an attempt to investigate the possible metabolic effects of eplerenone.

\section{Safety issues}

EMPHASIS-HF is also designed to investigate whether the riskbenefit ratio of adding eplerenone is acceptable in mild-to-moderate HF. Spironolactone, even at modest doses, has undesirable side effects, particularly gynaecomastia, which is not observed with the more selective MR-blocker eplerenone. Both have hyperkalaemia as an obligate adverse effect, reflecting the renal tubular effects of MR blockade. Previous trials with eplerenone show that, with careful titration, there appears to be only a very modest increase of $<0.3 \mathrm{mmol} / \mathrm{L}$ in plasma potassium, even at high doses $(200 \mathrm{mg}){ }^{27}$ Similar to the RALES and EPHESUS trials, the carefully set inclusion/exclusion criteria for EMPHASISHF are intended to minimize the risk of hyperkalaemia and worsening renal function. Furthermore, the investigators are instructed to use a pre-defined dose titration algorithm based on serum potassium and creatinine levels measured at each visit. However, there is still a real risk of hyperkalaemia in elderly patients and/or diabetic patients with a low eGFR, particularly at higher doses and/or when potassium supplementation is used. ${ }^{28}$ 
Specific serious safety concerns over hyperkalaemia and renal function will be closely monitored. Hospitalization for worsening renal function and/or hyperkalaemia will be prospectively documented and adjudicated.

In patients with mild HF receiving optimal therapy including $\beta$-blockers, the balance between risk and benefit might not be as favourable as in the RALES and EPHESUS trials due to the patients' lower absolute risk of a CV event and likely lower absolute reduction of $\mathrm{CV}$ risk with eplerenone. However, a subgroup analysis of the Candesartan in Heart failure: Assessment of Reduction in Mortality and morbidity (CHARM)-Added trial has shown that in $\mathrm{HF}$ patients already taking spironolactone as well as an ACE-I and $\beta$-blocker, the addition of the ARB candesartan appeared to provide added benefit at acceptable risk. ${ }^{29}$

\section{Conclusion}

Heart failure with low LVEF but mild symptoms is a frequent condition that is still associated with poor outcome. Few trials have exclusively enrolled patients with this profile. If positive, the results of EMPHASIS-HF would extend the use of $A B$ in HF with low LVEF. They would provide more safety data and expand the range of patients with low LVEF eligible for an $A B$, as well as provide additional safety information that should be of value in guiding clinical practice.

\section{Funding}

The EMPHASIS-HF study is funded by Pfizer, Inc.

Conflict of interest: F.Z. reports receiving consulting honoraria from Servier, AstraZeneca, Pfizer, Boehringer Ingelheim, Novartis, Abbott, Relypsa, Resmed, Merck, Daiichi Sankyo, Takeda, Boston Scientific, Medtronic, and Otsuka. J.J.V.M. and D.J.V.V. are members of the EMPHASIS-HF Executive Committee, which is supported by Pfizer. H.K. reports no conflicts. K.S. has received research support from the sponsor but has no other financial conflicts. H.S. is an employee of Pfizer. J.V. is currently employed by Pfizer and owns stock in Pfizer, Inc., the makers of eplerenone. B.P. is a consultant for Pfizer (eplerenone), Merck, Bayer, Novartis, Takeda, AstraZeneca, Sankyo, ONO, EZ Healthcare, and Forrest Laboratories, is a consultant, and holds stock options in Relypsa, BG Medicine, and Nile Therapeutics, and has received grants from Medtronic, Bayer, Novartis, and Abbott.

\section{Appendix}

Executive Steering Committee: Helmut Drexler (Hannover) (deceased), Dirk J. van Veldhuisen (Groningen), Henry Krum (Melbourne), Bertram Pitt (Ann Arbor) (Co-Chairman), Faiez Zannad (Nancy) (Co-Chairman), John McMurray (Glasgow), Karl Swedberg (Göteborg). Endpoint Adjudication Committee: Willem J. Remme (Rhoon) (Chair), Jan Hein Cornel (Schoorl), Per Hildebrandt (Frederiksberg), Jaromir Hradec (Prague), Vlacheslav Mareev (Moscow), K. Srinath Reddy (New Delhi), Andrew Sindone (Eastwood), Felipe Martinez (Córdoba), Angeles Alonso Garcia (Madrid). Data Safety Monitoring Committee: Lars Wilhelmsen (Göteborg) (Chair), Henry J. Dargie (Glasgow), Luigi Tavazzi (Pavia), Stuart Pocock (London), Alain Liezorovic (Lyon).

Investigators: I. Edes, T. Forster, I. Preda, K. Simon, K. Zámolyi, K. Sastry Bhagavatula, S. Sathe, P. Vadagenalli, S. lyengar,
K. Chockalingam, A. Mullasari, N. Sinha, D. Cross, A.P. Sindone, D. Kosturakis, J. Calvillo, M. Chiariello, H. Linkova, M. Aschermann, J. Munz, J. Spinar, J. Murin, P. Loviska, Z. Mikes, E. Goncalvesova, P. Agostoni, B.B. Singh, L. Groch, J. Smid, J. Vojacek, O. Jerabek, D. Brecka, R. Uhliar, J. Cardoso, A. Andrade, I. Moreira, N. Lousada, Á. Abreu, C. Fonseca, L. Providência, M. Trabulo, V. M. Gil, F.P. Papua, C. Mendonca, R. Wachter, J. Mueller-Ehmsen, J.-U. Roehnisch, R. Willenbrock, S. Erbs, R. Winkler, V. Mitrovic, C. Oezcelik, H. Schunkert, K. Wollert, U. Krueger, B.R. Winkelmann, R. Jozwa, A. Rynkiewicz, K. Kawecka-Jaszcz, M. Krzeminska-Pakula, H.W. Prozesky, M. Dluzniewski, J. Korewicki, M. Wierzchowiecki, S. Waich, J. Mancebo, I. Méndoza, C.J. Vaughan, K.M. McDonald, M. Modena, M. Volterrani, M.A. Denvir, P.J. Keeling, R. Senior, M. Barlow, A. Kardos, A. Al-Mohammad, A.J. Manolis, K. Vasiliadis, H. Karvounis, C. Zaboulis, I. Nanas, S. Adamopoulos, I. Kalikazaros, D. Kremastinos, A.A. Jennifer Adgey, A.A. Khokhar, R.M. Egdell, A.B. Bridges, P. Terrosu, H. Theron, Z.P. Ding, C. Tamburino, L. Gaspar, V. Cirrincione, G. Sinagra, F. Masini, G.P. Aroutyunov, D.P. Naidoo, K. Sliwa-Hahnle, S. Philipp, K. Sotirellos, G.S. Wander, S.G. Williams, R. Spacek, M. Anguita, J.R.G. Juanatey, E. Galve, M. Vida, E. de Teresa, K.S. Sastry Bhagavatula, M. Senni, A.N. Parkhomenko, O.I. Dyadyk, V.F. Kubyshkin, L.G. Kononenko, G.A. Ignatenko, Cheuk-Man Yu, S. Lee, L.G. Voronkov, S.A. Tykhonova, M.V. Rishko, A. Bazylevych, V.I. Tseluyko, I. Monte, J.B.R.M. de Swart, D.M. Nicastia, F.F. Willems, P.H.J.M. Dunselman, M.C.G. Daniëls, D.J.A. Lok, A. Dirkali, J.A. Kragten, H.J.M. Thijssen, A.A. Voors, A.H.E.M. Maas, H. Heuer, U. Ahremark, M. Fu, B. Andersson, I.I. Sakharchuk, G.V. Dzyak, H.R. Michels, P.M.M. Orbe, M.V. Perepelytsya, M. Komajda, P. Attali, A. Bonneau, B.D. Hautefeuille, F. Funck, P. Gibelin, L. Hittinger, M. Carrageta, S. Berglund, U. Axelsson, J.L. Serra, U. Dahlstrom, W. Van Mieghem, B. Marchandise, A.C. Van Dorpe, F.P.P. Charlier, P. Dendale, J. Vanhaecke, G.F. Gensini, E. Maupas, G.Q. Villani, G. Roul, J.-N. Trochu, K. Boman, P. Vasko, G. De Keulenaer, D. Rucka, V. Vizir, T.O. Pertseva, O.V. Kuryata, G.S. Popik, J.M. Thierer, M. Lindgren, D. Nul, G. Boffa, N.P. Shilkina, Y.B. Karpov, A. Stenberg, A. Johansson, H. Prantare, P. Poliacik, F. Marenne, N. Bazargani, D.E. Allaf, J.-L. Boreux, V. Ambrovicova, F. Petersen-Aranguren, G. Stehn, J. Takacs, K. Swedberg, J.J. McMurray, O.M. Girina, G.I. Obraztsova, E.V. Shlyakhto, A. Skvortsov, R.G. Velasco-Sanchez, Y.P. Nikitin, W.A. Almahmeed, R. Leischik, A. Foerster, N. Franz, G.B. Bon, G.B. Ambrosio, Z. Gaciong, A. Karavidas, C. Czibok, P. Kycina, A. Philias, P. Nash, R. Ramani, I.S. Anand, D. Wencker, F.A. McGrew, D.A. Henderson, C.M. Schmalfuss, J.A. Lash, D.S. Primack, D. Moraes, W.R. Herzog, E.J. Kosinski, A.H. Wiseman, C.S. Breburda, R.J. Dahiya, C.B. Treasure, U. Thadani, J.-W. Ha, S.C. Murali, M.R. Berk, J.-H. Shin, M. Nallasivan, A.R. Flores, F.L. Lally, D. Rawitscher, L. Stoletniy, K. Gindin, V.A. Kostenko, B.D. Bertolet, R. Sangrigoli, E. Philbin, A. Cruz-Diaz, R.S. McKelvie, M.N. Walsh, J.M. Arnold, S.M. Kouz, S. Lepage, G. Proulx, T. Huynh, E. O'Meara, R.C. Capodilupo, C.D. Vogel, J.L. Anderson, S.-C. Chae, E. Bayram-Llamas, M. Ogorek, M. Ujda, S.M. Mohiuddin, W.S. Colucci, R.J. Katz, S.H. Dunlap, E. Winkel, R.M. Vicari, R.D. Blonder, C. Sauve, T. Olive, M.P. Galinier, Y. Jobic,

\section{References}

1. Funder JW. Reconsidering the roles of the mineralocorticoid receptor. Hypertension 2009;53:286-290.

2. Rocha R, Rudolph AE, Frierdich GE, Nachowiak DA, Kekec BK, Blomme EA, McMahon EG, Delyani JA. Aldosterone induces a vascular inflammatory phenotype in the rat heart. Am J Physiol Heart Circ Physiol 2002;283:H1802-H1810.

3. Silvestre JS, Heymes C, Oubenaissa A, Robert V, Aupetit-Faisant B, Carayon A, Swynghedauw B, Delcayre C. Activation of cardiac aldosterone production in 
rat myocardial infarction: effect of angiotensin II receptor blockade and role in cardiac fibrosis. Circulation 1999;99:2694-2701.

4. Delcayre C, Swynghedauw B. Molecular mechanisms of myocardial remodeling. The role of aldosterone. I Mol Cell Cardiol 2002;34:1577-1584.

5. Struthers AD. The clinical implications of aldosterone escape in congestive heart failure. Eur J Heart Fail 2004;6:539-545.

6. Sato A, Saruta T. Aldosterone breakthrough during angiotensin-converting enzyme inhibitor therapy. Am J Hypertens 2003;16:781-788.

7. Fung JW, Yu CM, Yip G, Chan S, Yandle TG, Richards AM, Nicholls MG, Sanderson JE. Effect of beta blockade (carvedilol or metoprolol) on activation of the renin-angiotensin-aldosterone system and natriuretic peptides in chronic heart failure. Am J Cardiol 2003;92:406-410.

8. McKelvie RS, Yusuf S, Pericak D, Avezum A, Burns RJ, Probstfield J, Tsuyuki RT, White M, Rouleau J, Latini R, Maggioni A, Young J, Pogue J. Comparison of candesartan, enalapril, and their combination in congestive heart failure: randomized evaluation of strategies for left ventricular dysfunction (RESOLVD) pilot study. The RESOLVD Pilot Study Investigators. Circulation 1999;100:1056-1064.

9. Boccanelli A, Cacciatore G, Mureddu GF, de Simone G, Clemenza F, De Maria R, Di Lenarda A, Gavazzi A, Latini R, Masson S, Porcu M, Vanasia M, Gonzini L, Maggioni AP. Baseline characteristics of patients recruited in the AREA IN-CHF study (Antiremodelling Effect of Aldosterone Receptors Blockade with Canrenone in Mild Chronic Heart Failure). J Cardiovasc Med (Hagerstown) 2007;8: 683-691.

10. Cohn JN, Anand IS, Latini R, Masson S, Chiang YT, Glazer R. Sustained reduction of aldosterone in response to the angiotensin receptor blocker valsartan in patients with chronic heart failure: results from the Valsartan Heart Failure Trial. Circulation 2003;108:1306-1309.

11. Pitt B, Zannad F, Remme WJ, Cody R, Castaigne A, Perez A, Palensky J, Wittes J. The effect of spironolactone on morbidity and mortality in patients with severe heart failure. Randomized Aldactone Evaluation Study Investigators. N Engl J Med 1999;341:709-717.

12. Pitt B, Remme W, Zannad F, Neaton J, Martinez F, Roniker B, Bittman R, Hurley S, Kleiman J, Gatlin M. Eplerenone, a selective aldosterone blocker, in patients with left ventricular dysfunction after myocardial infarction. N Engl J Med 2003;348: 1309-1321.

13. Dickstein K, Cohen-Solal A, Filippatos G, McMurray JJ, Ponikowski P, Poole-Wilson PA, Stromberg A, van Veldhuisen DJ, Atar D, Hoes AW, Keren A, Mebazaa A, Nieminen M, Priori SG, Swedberg K. ESC guidelines for the diagnosis and treatment of acute and chronic heart failure 2008: the Task Force for the diagnosis and treatment of acute and chronic heart failure 2008 of the European Society of Cardiology. Developed in collaboration with the Heart Failure Association of the ESC (HFA) and endorsed by the European Society of Intensive Care Medicine (ESICM). Eur J Heart Fail 2008;10:933-989.

14. Effect of metoprolol $C R / X L$ in chronic heart failure: Metoprolol CR/XL Randomised Intervention Trial in Congestive Heart Failure (MERIT-HF). Lancet 1999;353: 2001-2007.

15. Lakhdar R, Al-Mallah MH, Lanfear DE. Safety and tolerability of angiotensinconverting enzyme inhibitor versus the combination of angiotensin-converting enzyme inhibitor and angiotensin receptor blocker in patients with left ventricular dysfunction: a systematic review and meta-analysis of randomized controlled trials. J Card Fail 2008;14:181-188.

16. Williams RE. The effect of neurohormonal antagonists in reducing heart failure hospitalizations. Curr Med Res Opin 2006;22:139-150.
17. Effect of enalapril on mortality and the development of heart failure in asymptomatic patients with reduced left ventricular ejection fractions The SOLVD Investigators. N Engl J Med 1992;327:685-691.

18. Gustafsson F, Schou M, Videbaek L, Dridi N, Ryde H, Handberg J, Hildebrandt PR Incidence and predictors of hospitalization or death in patients managed in multidisciplinary heart failure clinics. Eur J Heart Fail 2009;11:413-419.

19. Solomon SD, Dobson J, Pocock S, Skali H, McMurray JJ, Granger CB, Yusuf S, Swedberg K, Young JB, Michelson EL, Pfeffer MA. Candesartan in Heart failure: Assessment of Reduction in Mortality and morbidity (CHARM) Investigators. Influence of nonfatal hospitalization for heart failure on subsequent mortality in patients with chronic heart failure. Circulation 2007;116:1482-1487.

20. Wang NC, Maggioni AP, Konstam MA, Zannad F, Krasa HB, Burnett JC Jr, Grinfeld L, Swedberg K, Udelson JE, Cook T, Traver B, Zimmer C, Orlandi C, Gheorghiade M. Clinical implications of QRS duration in patients hospitalized with worsening heart failure and reduced left ventricular ejection fraction. JAMA 2008;299:2656-2666.

21. Boccanelli A, Mureddu GF, Cacciatore G, Clemenza F, Di Lenarda A, Gavazzi A, Porcu M, Latini R, Lucci D, Maggioni AP, Masson S, Vanasia M, de Simone G. Antiremodelling effect of canrenone in patients with mild chronic heart failure (AREA IN-CHF study): final results. Eur J Heart Fail 2009;11:68-76.

22. Chan AK, Sanderson JE, Wang T, Lam W, Yip G, Wang M, Lam YY, Zhang Y, Yeung L, Wu EB, Chan WW, Wong JT, So N, Yu CM. Aldosterone receptor antagonism induces reverse remodeling when added to angiotensin receptor blockade in chronic heart failure. J Am Coll Cardiol 2007;50:591-596.

23. Berry C, Murphy NF, De Vito G, Galloway S, Seed A, Fisher C, Sattar N, Vallance $\mathrm{P}$, Hillis WS, McMurray J. Effects of aldosterone receptor blockade in patients with mild-moderate heart failure taking a beta-blocker. Eur J Heart Fail 2007;9:429-434.

24. Macdonald JE, Kennedy N, Struthers AD. Effects of spironolactone on endothelial function, vascular angiotensin converting enzyme activity, and other prognostic markers in patients with mild heart failure already taking optimal treatment. Heart 2004;90:765-770.

25. Ezekowitz JA, McAlister FA. Aldosterone blockade and left ventricular dysfunction: a systematic review of randomized clinical trials. Eur Heart J 2009;30: 469-477.

26. Udelson JE, Feldman AM, Greenberg B, Pitt B, Mukherjee R, Solomon HA, Konstam MA. Randomized, double-blind, multicenter, placebo-controlled study evaluating the effect of aldosterone antagonism with eplerenone on ventricular remodeling in patients with mild-to-moderate heart failure and left ventricular systolic dysfunction. Cir Heart Fail. Published online ahead of print 18 March 2010.

27. Levy DG, Rocha R, Funder JW. Distinguishing the antihypertensive and electrolyte effects of eplerenone. J Clin Endocrinol Metab 2004;89:2736-2740.

28. Juurlink DN, Mamdani MM, Lee DS, Kopp A, Austin PC, Laupacis A, Redelmeier DA. Rates of hyperkalemia after publication of the Randomized Aldactone Evaluation Study. N Engl J Med 2004;351:543-551.

29. Weir RA, McMurray JJ, Puu M, Solomon SD, Olofsson B, Granger CB, Yusuf S, Michelson EL, Swedberg K, Pfeffer MA. Efficacy and tolerability of adding an angiotensin receptor blocker in patients with heart failure already receiving an angiotensin-converting inhibitor plus aldosterone antagonist, with or without a beta blocker. Findings from the Candesartan in Heart failure: Assessment of Reduction in Mortality and morbidity (CHARM)-Added trial. Eur J Heart Fail 2008;10:157-163. 